\title{
KEPATUHAN PENATALAKSANAAN CAIRAN \\ PADA PASIEN YANG MENJ ALANI TERAPI HEMODIALISIS \\ DI RUMAH SAKIT SWASTA YOGYAKARTA
}

\author{
Yuliana Dyah Ayu Verita Kusumaningrum ${ }^{1,}$ Th Tatik Pujiastuti ${ }^{2}$ \\ 1)2) STIKes Panti Rapih, J1. Tantular No.401, Condongcatur, Kec. Depok, Kabupaten \\ Sleman, DIY 55281, email: tatik_pujiastuti@stikespantirapih.ac.id
}

\begin{abstract}
ABSTRAK
Latar Belakang : Hemodialisis merupakan salah satu metode terapi bagi klien end-stage renal disease. Salah satu masalah pada pasien hemodialisis adalah kelebihan cairan tubuh. Pengendalian cairan merupakan solusi efektif untuk mencegah komplikasi yang disebabkan oleh kelebihan cairan tubuh. Oleh karena itu, kepatuhan tentang penatalaksanaan cairan merupakan hal yang penting untuk memperbaiki kondisi pasien hemodialisis.
\end{abstract}

Tujuan : Penelitian ini bertujuan untuk menggambarkan kepatuhan penatalaksanaan cairan serta mengetahui hubungan lama menjalani hemodialisis dan IDWG dengan tingkat kepatuhan penatalaksanaan cairan pasien hemodialisis.

Metode : Penelitian ini merupakan deskriptif kuantitati dengan jumlah sampel 30 pasien hemodialisis, diambil secara random. Pengumplan data menggunakan kuesioner. Analisis data secara univariat menggunakan analisis prosentase dan bivariat menggunakan korelasi spearman untuk mengetahui hubungan lama menjalani hemodialisis dan IDWG dengan tingkat kepatuhan.

Hasil : Secara statistik ada $60 \%$ pasien mempunyai tingkat kepatuhan baik, $40 \%$ memiliki tingkat kepatuhan cukup, dan masih ada 10\%yang mempunyai tingkat kepatuhan tidak baik. Diketahui pula bahwa ada $24 \%$ dari pasien yang mempunyai tingkat kepatuhan baik memiliki pengalaman hemodialisis $<4$ tahun dan $25 \%$ memiliki IDWG $<3 \mathrm{~kg}$. Diketahui pula bahwa tidak ada korelasi yang signifikan antara lama hemodialisis dengan tingkat kepatuhan penatalaksanaan cairan dengan $\mathrm{p}$ value $0,521>0,05$ dan tidak ada korelasi yang signifikan antara IDWG dengan tingkat kepatuhan penatalaksanaan cairan dengan $p$ value $0,422>0,05$.

Simpulan: Penatalaksanaan cairan penting untuk mengontrol IDWG. Oleh karena itu sangat perawat diharapkan memberikan edukasi yang intensif untuk meningkatkan kepatuhan dalam penatalaksanaan cairan pada pasein hemodialisis.

Kata kunci : Hemodialisis, Kepatuhan, Penatalaksanaan Cairan , IDWG (Interdialysis Weight Gain) 


\begin{abstract}
Background: Hemodialysis is one of the therapeutic methods for clients with end-stage renal disease. One of the problems in hemodialysis patients is the excess volume of body fluids. Fluid control is a solution to prevent complications due to excess volume of fluid.Therefore, adherence about fluid management is important to improve condition of hemodialysis patients. Objective: This study aims to describe adherence and the corelation of duration haemodialysis and IDWG with adherence of fluid management in hemodialysis patients
\end{abstract}

Methods: This is quantitative descriptive method. Thirty sample was randomly. The data collection with questionnaire. Data analysis techniques are univariate using percentages and bivariat spearman corelation to describe the results of the study

Result: There is a good adherence level in the management of fluid intake $60 \%$, enough in adherence $40 \%$, and not good in adherence $10 \%$. It was also known that $24 \%$ of patients who a good adherent in fluid management had hemodialysis $<4$ years and $25 \%$ have an IDWG $<3$ $\mathrm{kg}$. There are no corelation of duration of haemodialysis $\mathrm{p}$ value $0,521>0,05$ and IDWG $\mathrm{p}$ value $0,422>0,05$ with adherence of fluid management in hemodialysis patients.

Conclusion: It is assumed that adherence to fluid management is important for controlling IDWG in hemodialysis patients. Based on result of this study, this is important for nurses to take more intensive education to improve the adherence of hemodialysis patients in fluid management.

Keyword's: Hemodialysis, Adherence, Fluid management, IDWG (Interdialysis Weight Gain)

\section{PENDAHULUAN}

Hemodialisis merupakan salah satu metode terapi bagi klien end-stage renal disease yang menggantikan ginjal dalam ekskresi. Hemodialisis digunakan untuk memperbaiki ketidak seimbangan cairan dan elektrolit dan untuk mengeluarkan sisa produk metabolisme (Lewis et al., 2011). Jumlah pasien hemodialisis selalu meningkat setiap tahun. Berdasarkan data yang diperoleh dari Indonesian Renal Registry (IRR) (2017), menyebutkan bahwa di Indonesia, pada tahun 2016 terdapat 25.446 pasien baru yang menjalani hemodialisis dan pada tahun 2017 jumlah pasien yang menjalani hemodialisa 30.831 orang. Jumlah ini mengalami peningkatan sebanyak 5.385 orang atau 21,16\% (IRR, 2017).

Pasien hemodialisis memiliki banyak hal yang harus diperhatikan diantaranya pembatasan asupan cairan. Pembatasan asupan cairan perlu dilakukan pada pasien hemodialisis kerena dapat menyebabkan tubuh menjadi bengkak, gagal jantung, dan edema pulmo 
(Smeltzer \& Bare, 2014). Pembatasan asupan cairan akan mengubah gaya hidup dan dirasakan pasien sebagai keterbatasan. Pembatasan cairan sering kali sulit dilakukan oleh pasien, terutama jika mereka mengkonsumsi obat-obatan yang membuat membran mukosa kering seperti diuretik, sehingga menyebabkan rasa haus dan pasien berusaha untuk minum (Sepdianto, Suprajitno, Usmiyati, 2017). Keadaan tersebut dikarenakan dalam kondisi normal manusia tidak dapat bertahan lebih lama tanpa asupan cairan dibandingkan dengan makanan.

Pasien dengan terapi hemodialisis yang tidak mampu mengontrol pembatasan intake cairan mengakibatkan adanya peningkatan Interdialytic Weight Gain (IDWG), yang merupakan peningkatan volume cairan dan ditandai dengan peningkatan berat badan (Ningsih, Endang, Agus, 2012). Peningkatan IDWG melebihi 5\% dari berat badan atau lebih dari 1-2 $\mathrm{kg}$ diatas berat badan ideal akan menyebabkan komplikasi seperti, hipertensi, hipotensi intradialisis, edema, ronchi basah dalam paru-paru, kelopak mata yang bengkak, sesak nafas, hipertropi pada ventrikel kiri dan mengakibatkan respon fisik pasien cepat lelah, aktivitas fisik juga mengalami gangguan baik pada saat beraktivitas ringan maupun sedang bahkan dapat menyebabkan kematian. Selain itu apabila berat badan pasien dibawah berat badan ideal akan muncul gejala dehidrasi dan atau deplesi volume seperti hipotensi, kram, hipotensi postural atau pusing (Ignatavicius \& Workman, 2010). Oleh karena itu, pasien yang menjalani terapi hemodialisis harus patuh terhadap penatalaksanaan cairan sesuai yang telah ditentukan oleh tenaga kesehatan.

Kepatuhan terhadap pengontrolan diet dan pembatasan asupan cairan merupakan faktor yang sangat penting dalam menentukan tingkat kesehatan dan kesejahteraan pasien dengan hemodialisis kronis (Hadi \& Wantonoro, 2015). Sebagai seorang perawat, perlu mengetahui tingkat kepatuhan pasien dengan hemodialisis terhadap penatalaksanaan cairannya agar perawat bisa mengontrol asupan cairan pasien yang dikonsumsi serta melakukan evaluasi terhadap intervensi yang telah dilakukan terhadap pasien sehingga meminimalisir terjadinya komplikasi bahkan kematian.

Berdasarkan studi pendahuluan yang dilakukan peneliti di Rumah Sakit Swasta di Yogyakarta pada bulan November 
2017, jumlah kunjungan pasien yang menjalani hemodialisis meningkat setiap tahunnya hingga mencapai $31,1 \%$ dari tahun 2016. Hasil wawancara terhadap penanggung jawab Ruang Hemodialisa dan studi dokumentasi di Rumah Sakit tersebut didapatkan data dari 102 pasien yang menjalani hemodialisa terdapat $29,4 \%$ atau sebanyak 30 pasien yang mengalami peningkatan IDWG lebih dari 5\% dalam 1 kali periode tindakan hemodialisa. Kondisi ini diduga akibat kurang mampu mengendalikan asupan cairan.

Berdasarkan pemaparan di atas, peneliti akan melihat bagaimana kepatuhan pasien hemodialisis dalam penatalaksanaan cairan. Peneliti akan melihat kepatuhan pasien serta korelasi lama menjalani hemodialisis dan IDWG dengan kepatuhan dalam penatalaksanaan jenis dan jumlah cairan pada pasien yang menjalani hemodialisis di Rumah Sakit Swasta Yogyakarta".

\section{METODE PENELITIAN}

Penelitian ini merupakan penelitian deskriptif kuantitatif yang bertujuan melihat kepatuhan penatalaksanaan cairan serta hubungan lama menjalani hemodialisis dan IDWG dengan tingkat kepatuhan pada pasien yang menjalani hemodialisis.

Penelitian dilakukan di unit Hemodialisis sebuah rumah sakit swasta di Yogyakarta dengan melibatkan 30 responden yang diambil secara acak. Pengambilan data dilakukan dengan menggunakan kuesioner. Data dianalisis secara univariat menggunakan analisis deskriptif dilengkapi dengan tabel silang dan secara bivariat menggunakan korelasi spearman untuk mengetahui hubungan lama menjalani hemodialisis dan IDWG dengan tingkat kepatuhan.

\section{HASIL DAN PEMBAHASAN}

\section{Karakteristik Responden}

Tabel 1.

Distribusi Responden Berdasarkan Jenis Kelamin $(n=30)$

\begin{tabular}{lcc}
\hline Jenis kelamin & $\mathrm{n}$ & $\%$ \\
\hline Laki-laki & 24 & 80 \\
\hline Perempuan & 6 & 20 \\
\hline Total & 30 & 100 \\
\hline Sumber: Data Primer & &
\end{tabular}

Berdasarkan tabel 1. diketahui bahwa sebagian besar responden yaitu $80 \%$ yang menjalani terapi hemodialisis berjenis kelamin laki-laki. Hal ini menunjukkan laki-laki lebih beresiko 
terkena penyakit gagal ginjal tahap akhir dan menjalani hemodialisis.

Tabel 2.

Distribusi Frekuensi Reponden

Berdasarkan Umur $(n=30)$

\begin{tabular}{lcc}
\hline Umur & $\mathrm{n}$ & $\%$ \\
\hline$<40$ tahun & 5 & 17 \\
\hline $40-60$ tahun & 19 & 63 \\
\hline$>60$ tahun & 6 & 20 \\
\hline Total & 30 & 100 \\
\hline
\end{tabular}

Sumber : Data Primer

Berdasarkan tabel 2, menunjukkan bahwa prosentase tertinggi responden yang menjalani hemodialisis berada pada umur 40-60 tahun yakni sebesar 63\%. Hal ini menunjukkan bahwa penyakit gagal ginjal tahap akhir lebih banyak menyerang pada rentang umur 40-60 tahun.

Tabel 3.

Distribusi Responden Berdasarkan Lama Menjalani Hemodialisis $(\mathrm{n}=30)$

\begin{tabular}{lll}
\hline $\begin{array}{l}\text { Lama Menjalani } \\
\text { Hemodialisis }\end{array}$ & $\mathrm{n}$ & $\%$ \\
\hline$\leq 4$ tahun & 25 & 85,3 \\
\hline$>4$ tahun & 5 & 16,7 \\
\hline Total & 30 & 100 \\
\hline
\end{tabular}

Sumber : Data Primer

Berdasarkan tabel 3. diketahui bahwa sebagian besar responden yaitu $85,3 \%$ menjalani hemodilaisis $\leq 4$ tahun, sedangkan hanya $16,7 \%$ yang $>4$ tahun. Data tersebut menunjukkan bahwa responden mempunya peluang untuk lebih meningkatkan kualitas hidupnya dengan patuh terhadap penatalaksanaan cairan.

Tabel 4.

Distribusi Responden Berdasarkan IDWG $(\mathrm{n}=30)$

\begin{tabular}{lcc}
\hline $\begin{array}{l}\text { Lama Menjalani } \\
\text { Hemodialisis }\end{array}$ & $\mathrm{n}$ & $\%$ \\
\hline$<3 \mathrm{~kg}$ & 18 & 60 \\
\hline$\geq 3 \mathrm{~kg}$ & 12 & 40 \\
\hline Total & 30 & 100 \\
\hline
\end{tabular}

Sumber : Data Primer

Berdasarkan tabel 4, diketahui bahwa sebagian besar responden yaitu $60 \%$ mempunyai IDWG $<3 \mathrm{~kg}$, sedangkan ada $40 \%$ yang mempunyai IDWG $\geq 3 \mathrm{~kg}$. Data tersebut menunjukkan bahwa sebagian besar responden mampu mengontrol cairan tubuhnya sehingga asumsinya patuh terhada penatalaksanaan cairan selama interdialisis.

Tabel 5.

Distribusi Tingkat Kepatuhan Penatalaksanaan Cairan Pada Pasien Yang Menjalani Terapi Hemodialisis $(n=30)$

\begin{tabular}{lcc}
\hline Tingkat Kepatuhan & $\mathrm{n}$ & $\%$ \\
\hline Baik & 18 & 60 \\
Cukup & 12 & 40 \\
Kurang & 0 & 0 \\
\hline Total & 30 & 100 \\
\hline Sumber : Data Primer & &
\end{tabular}

Berdasarkan tabel 5 didapatkan data bahwa sebagian besar responden yakni $60 \%$ memiliki tingkat kepatuhan penatalaksanaan cairan yang baik. Hal ini 
menunjukkan banyak responden yang mampu mengelola asupan cairan dalam sehari-hari.

\section{Tabel 6.}

Tingkat Kepatuhan Penatalaksanaan Cairan Berdasarkan Lama Hemodialisis $(\mathrm{n}=30)$

\begin{tabular}{|c|c|c|c|c|c|c|c|c|}
\hline \multirow{3}{*}{$\begin{array}{l}\text { Lama } \\
\text { HD }\end{array}$} & \multicolumn{6}{|c|}{ Tingkat Kepatuhan } & \multirow{2}{*}{\multicolumn{2}{|c|}{ Total }} \\
\hline & \multicolumn{2}{|c|}{ Baik } & \multicolumn{2}{|c|}{ Cukup } & \multicolumn{2}{|c|}{ Kurang } & & \\
\hline & $\mathrm{n}$ & $\%$ & $\mathrm{n}$ & $\%$ & $\mathrm{n}$ & $\%$ & $\mathrm{n}$ & $\%$ \\
\hline$\leq 4$ th & 12 & 80 & 13 & 20 & 0 & 0 & 15 & 100 \\
\hline$>4$ th & 3 & 86,7 & 2 & 13,3 & 0 & 0 & 15 & 100 \\
\hline
\end{tabular}

Sumber : Data Primer

Berdasarkan tabel 6, diketahui bahwa hampir semua responden yang menjalani hemodialisis $\leq 4$ mempunyai tingkat kepatuhan baik yaitu $80 \%$ dan ada 20\% memiliki tingkat kepatuhan cukup. Diketahui pula bahwa Sebagian besar responden dengan lama hemodialisis $>4$ tahun memiliki tingkat kepatuhan baik dan ada $13,3 \%$ responden yang memiliki tingkat kepatuhan cukup serta tidak ada responden yang memiliki tingkat kepatuhan kurang.

Tabel 7.

Tingkat Kepatuhan Penatalaksanaan Cairan Berdasarkan IDWG $(n=30)$

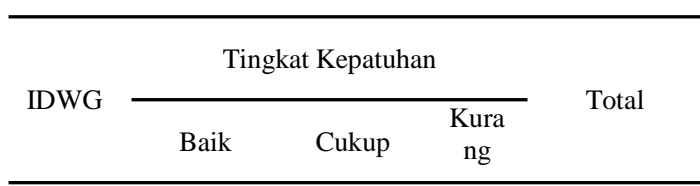

\begin{tabular}{|c|c|c|c|c|c|c|c|c|}
\hline & $\mathrm{n}$ & $\%$ & $\mathrm{n}$ & $\%$ & $\mathrm{n}$ & $\%$ & $\mathrm{n}$ & $\%$ \\
\hline$<2 \mathrm{~kg}$ & $\begin{array}{l}1 \\
0\end{array}$ & 55,6 & 8 & 44,4 & 0 & 0 & 18 & 100 \\
\hline$\geq 2 \mathrm{~kg}$ & 5 & 41,6 & 7 & 58,3 & 0 & 0 & 12 & 100 \\
\hline
\end{tabular}

Sumber : Data Primer

Berdasarkan tabel 7, diketahui bahwa responden yang memiliki IDWG $\geq 2 \mathrm{~kg}$ yaitu $41,6 \%$ memiliki tingkat kepatuhan yang baik dan 58,3\% memiliki tingkat kepatuhan cukup. Diketahui pula bahwa responden yang memiliki IDWG $<2 \mathrm{~kg}$ ada $55.6 \%$ memiliki tingkat kepatuhan baik dan $44,4 \%$ responden yang memiliki tingkat kepatuhan cukup serta tidak ada responden yang memiliki tingkat kepatuhan kurang.

Tabel 8.

Hasil Uji Korelasi Lama Hemodialisis dan IDWG dengan Tingkat Kepatuhan Penatalaksanaan Cairan Pasien Hemodialisis $(\mathrm{n}=30)$

\begin{tabular}{ll}
\hline \multirow{2}{*}{ Variabel } & \multicolumn{1}{c}{ P Value } \\
\cline { 2 - 2 } & \\
\hline Lama Hemodialisis & 0,638 \\
\hline IDWG & 0,473 \\
\hline
\end{tabular}

Berdasarkan tabel 8, di atas, diketahui bahwa tidak ada korelasi yang signifikan antara lama hemodialisis dengan tingkat kepatuhan penatalaksanaan cairan dengan ditunjukkan nilai $p$ value 0,521 >0,05. Diketahui pula bahwa tidak ada korelasi 
yang signifikan antara IDWG dengan tingkat kepatuhan penatalaksanaan cairan dengan ditunjukkan nilai $p$ value $0,422>0,05$.

Berdasarkan hasil penelitian, secara statistik diperoleh data $60 \%$ responden memiliki tingkat kepatuhan yang baik dan ada $40 \%$ memiliki tingkat kepatuhan yang cukup dalam penatalaksanaan cairan. Menurut Beyebach, Neipp, García-Moreno, González-Sánchez (2018), kepatuhan merupakan hal penting karena dapat menurunkan problematika akibat penurunan fungsi ginjal yang dialaminya. Tingkat kepatuhan merupakan sikap yang ditunjukkan oleh pasien yang menjalani hemodialisis untuk mematuhi pembatasan asupan cairan sesuai yang diprogramkan oleh petugas kesehatan. Hasil penelitian ini menunjukkan bahwa sebagian besar responden yang menjalani terapi hemodialisis memiliki kepatuhan yang baik dalam pembatasan asupan cairan. Hasil penelitian ini sejalan dengan peneltian yang dilakukan oleh Novitasari \& Anita (2015) yang menyatakan bahwa sebanyak $71,7 \%$ responden termasuk dalam kategori patuh terhadap penatalaksanaan cairan.
Menurut Hadi \& Wantonoro (2015), kepatuhan dalam pembatasan asupan cairan merupakan faktor yang sangat penting dalam menentukan tingkat kesehatan dan kesejahteraan pasien dengan hemodialisis kronis. Pasien yang tidak mematuhi pembatasan asupan cairan dapat mengalami kenaikan berat badan yang cepat melebihi 5\%, edema, ronchi basah dalam paru-paru, kelopak mata yang bengkak, sesak nafas, dan hipertropi pada ventrikel kiri (Ningsih, Endang, Agus, 2012). Penumpukan cairan dalam tubuh menyebabkan fungsi kerja jantung dan paru-paru berat, yang berakibat pada respon fisik pasien cepat lelah dan sesak, aktivitas fisik juga mengalami gangguan baik pada saat beraktivitas ringan maupun sedang (Desitasari, utami, Misrawati, 2014). Berdasarkan pengalaman peneliti saat melakukan penelitian, beberapa pasien datang ke ruang hemodialisa dengan keadaan edema di kaki dan merasakan sesak nafas akibat ketidakpatuhannya dalam pembatasan asupan cairan.

Berdasarkan hasil penelitian diketahui bahwa ada $23 \%$ responden memiliki tingkat kepatuhan baik dalam penatalaksanaan jenis cairan, dan ada $10 \%$ yang kurang patuh pada 
penatalaksanaan jenis cairan. Hal ini menunjukkan bahwa kepatuhan pasien perlu ditingkatkan. Jenis cairan yang harus dibatasi pada pasien hemodialis ialah yang mengandung natrium, kalium, fosfat karena akan menyebabkan terjadinya edema dan hipertensi. Berdasarkan pengalaman peneliti pada saat penelitian, beberapa pasien yang menjalani hemodialisis mengaku pernah memakan buah-buahan seperti pisang dan semangka lalu mereka menjadi pusing, lemas, dan merasa sesak nafas. Kondisi ini membahayakan pasien. Adanya responden dengan tingkat kepatuhan rendah dalam penatalaksanaan jumlah cairan menunjukkan bahwa responden memerlukan motivasi untuk mampu mengendalikan cairan. Menurut Savitri, Y. A., \& Parmitasari, D. L. N. (2015), dukungan keluarga mempunyai korelasi yang positif meingkatkan motivasi pasien untuk mengelola diet termasuk cairan.

Secara statistik diketahui bahwa dari 25 responden yang menjalani hemodialisis $\leq 4$ tahun ada $24 \%$ memiliki tingkat kepatuhan baik dan masih ada $12 \%$ yang kurang patuh. Sedangkan pada responden dengan lama hemodialisis $>4$ tidak ada yang kurang patuh. Berdasarkan hasil penelitian tersebut tampak bahwa pada pasien yang lebih lama menjalani hemodialisis lebih sedikit untuk tidak patuh, meskipun secara data tidak jauh perbedaannya dengan yang baru manjalani hemodialisis. Hasil penelitian ini sesuai dengan penelitian yang dilakukan oleh Rostanti, Bawotong, Onibala (2016) yang menyatakan bahwa pasien hemodialisis patuh terhadap segala sesuatu tentang hemodialisis paling baik pada pasien yang lama menjalani hemodialisis selama 1 tahun. Penelitian lain menyatakan bahwa pasien hemodialisis <24 bulan cenderung lebih patuh terhadap penatalaksanaan hemodialisis termasuk cairan (Maguno, 2014 dalam Pahrul \& Andamsari, 2018)

Berdasarkan hasil penelitian, diketahui pula bahwa responden yang memiliki IDWG $\geq 3 \mathrm{~kg}$ ataupun $<3 \mathrm{~kg}$, lebih dari separuh memiliki tingkat kepatuhan cukup dalam penatalaksanaan jenis cairan. Peneliti berpendapat pasien yang memiliki kenaikan berat badan intradialitik $<3 \mathrm{~kg}$ menunjukkan mereka mampu mengontrol asupan jenis cairan dalam sehari. Hal itu dapat disebabkan 
karena pasien hemodialisis menyadari akan dampak yang timbul jika tidak melakukan program pembatasan jenis cairan. Kasus yang paling sering dijumpai adalah pasien hemodialisis datang dengan keluhan sesak nafas dan terjadi edema apabila mereka tidak melakukan pembatasan jenis cairan seperti yang diprogramkan.

Pembatasan cairan bukan merupakan hal yang mudah. Beberapa pasien hemodialisis mengatakan bahwa membatasi jumlah cairan sulit dilakukan karena mereka mudah merasa haus terutama saat cuaca yang panas. Menurut Potter \& Perry (2009) pembatasan cairan seringkali sulit dilakukan oleh pasien, terutama jika mereka mengkonsumsi obat-obatan yang membuat membran mukosa kering seperti diuretik, sehingga menyebabkan rasa haus dan pasien berusaha untuk minum. Keadaan tersebut dikarenakan dalam kondisi normal manusia tidak dapat bertahan lebih lama tanpa asupan cairan dibandingkan dengan makanan.

Berdasarkan lama menjalani hemodialisis diketahui masih ada $8 \%$ memiliki tingkat kepatuhan kurang pada pasien dengan lama menjalani hemodialisis $\leq 4$ tahun sedangkan Pada pasien dengan lama hemodialisis > 4 tahun sebanyak 20\%. Hal tersebut menunjukkan bahwa semakin lama pasien menjalani hemodilalisis ada kecenderungan tidak patuh. Hasil penelitian ini sesuai dengan penelitian yang dilakukan oleh Manguma, Kapantau, Joseph (2014) bahwa pasien yang menjalani hemodialisis $\leq 4$ tahun memiliki peluang untuk patuh dibandingkan pada pasien yang menjalani hemodialisa $>4$ tahun. Hal serupa juga disampaikan oleh Hadi \& Wantonoro (2015) bahwa semakin lama menjalani hemodialisis maka kepatuhan pembatasan cairan semakin rendah demikian pula sebaliknya semakin baru menjalani hemodialisis maka kepatuhan pembatasan cairan semakin tinggi. Berdasarkan hasil penelitian terdapat kesesuaian dengan teori yang ada.

Berdasarkan IDWG diketahui ada $11 \%$ memiliki tingkat kepatuhan yang kurang dalam penatalaksanaan jumlah cairan pada pasien dengan IDWG $\geq 3 \mathrm{~kg}$, sedangkan pada pasien yang memiliki IDWG $<3 \mathrm{~kg}$ ada 8\%. Hal ini menunjukkan bahwa pasien hemodialisis yang memiliki IDWG $<3 \mathrm{~kg}$ lebih banyak yang patuh sehingga mampu mengontrol asupan jumlah cairan yang masuk dalam 
kesehariannya. Apabila pasien ditunjukkan nilai $p$ value 0,422 > 0,05.

hemodialisis memiliki kesadaran yang tinggi terhadap pentingnya pembatasan asupan jumlah cairan dalam sehari serta dampak yang timbul jika tidak melaksanakan program pembatasan tersebut juga memiiki peluang untuk patuh.

Secara statistik diketahui bahwa tidak ada korelasi yang signifikan antara lama hemodialisis dengan tingkat kepatuhan penatalaksanaan cairan dengan ditunjukkan nilai $p$ value 0,521 >0,05. Penelitian Izzati \& Annisha (2016 menguatkan bahwa tidak ada hubungan yang signifikan antara lama menjalani hemodialisis dengan kepatuhan dengan $p$ value 0,056. Hasil penelitan ini bertentangan dengan hasil penelitian Pahrul \& Andamsari (2018) yang menyatakan bahwa uji statistik ada hubungan antara lamanya menjalani hemodialisa dengan kepatuhan pembatasan asupan cairan dengan $p$ value 0,019 .

Secara statistik diketahui pula bahwa tidak ada korelasi yang signifikan antara IDWG dengan tingkat kepatuhan penatalaksanaan cairan dengan
Hal ini tampak bahwa pasien yang memiliki IDWG $>3 \mathrm{~kg}$ ataupun $<3 \mathrm{~kg}$, hampir separuh pasien patuh pada pembatasan cairan. Hal ini berarti ada faktor lain menyebabkan IDWG meningkat. Menurut Sepdianto, Prajitno, Usmiyati (2017), faktor utama yang berhubungan dengan peningkatan IDWG adalah kepatuhan terhadap asupan cairan. Selain faktor kepatuhan pasien dalam pembatasan mengkonsumsi cairan, faktor lain yang kemungkinan dapat meningkatkan penambahan berat badan di antara dua waktu dialisis diantaranya lama tindakan, kecepatan aliran hemodialisis, ultrafiltrasi, cairan dialisilat yang digunakan, dll (Wahyuni, Irwanti, Indrayana, 2014).

\section{KESIMPULAN DAN SARAN}

Kesimpulan

Kepatuhan penatalaksanaan cairan merupakan hal yang penting untuk pasien hemodialisis. Secara statistik sebagian besar responden $(60 \%)$ telah mempunyai tingkat kepatuhan baik dalam penatalaksanaan cairan, namun demikian masih ada sebagian kecil (10\%) yang mempunyai tingkat kepatuhan tidak baik. 
Diketahui pula bahwa tidak ada korelasi yang signifikan antara lama hemodialisis dan IDWG dengan tingkat kepatuhan penatalaksanaan cairan.

Saran

Mengingat pentingnya kepatuhan penatalaksanaan cairan pada pasien hemodialisis dan masih adanya pasien yang tidak patuh, maka perawat diharapkan memberikan edukasi yang lebih intensif untuk meningkatkan kepatuhan dalam penatalaksanaan cairan pada pasien hemodialisis.

\section{DAFTAR PUSTAKA}

Beyebach, M., Neipp, M. D. C., García-Moreno, M., \& González-Sánchez, I. (2018). IMPACT of nurses' solution-focused communication on the fluid adherence of adult patients on haemodialysis. J ournal of advanced nursing, 74(11): 26542657.

https://doi.org/10.1111/jan.13792

Desitasari, Utami,G.T., Misrawati. (2014). Hubungan Tingkat Pengetahuan, Sikap, dan Dukungan Keluarga Terhadap Kepatuhan Diet Pasien Gagal Ginjal Kronik yang Menjalani Hemodialisa. J urnal online mahasiswa perpustakaan fakultas keperawatan U niversitas Riau, Vol 1 No 2. Retrived from https://www.neliti.com/publication s/188331/hubungan-tingkatpengetahuan-sikap-dan-dukungankeluarga-terhadap-kepatuhan-diet

Hadi, S., \& Wantonoro, W. (2015). Hubungan Lama Menjalani Hemodialisis dengan Kepatuhan Pembatasan Asupan Cairan pada Pasien Gagal Ginjal Kronik di RS PKU Muhammadiyah Unit II Yogyakarta (Doctoral dissertation, STIKES'Aisyiyah Yogyakarta). Retrived from http://digilib.unisayogya.ac.id/id/ep rint/162

Ignatavicius, D.D., Workman, M.L. (2010). Medical Surgical Nursing : Patient Centered Collaborative Care. Sixth Edition. USA : Elseiver

Izzati, W., \& Annisha, F. (2017). FaktorFaktor Yang Berhubungan Dengan Kepatuhan Pasien Yang Menjalani Hemodialisis Di Ruang Hemodialisa Di Rsud Dr. Achmad Mochtar Bukittinggi Tahun 2015. 'AFIYAH, 3(1). Retrived from http://www.ejournal.stikesyarsi.ac.i d/index.php/JAV1N1/article/view/ 73

Indonesian Renal Registry (IRR).(2017). $10^{\text {th }}$ Report of Indonesian Renal Registry. Indonesian Renal Registry

Lewis, Sharon L., Dirksen, Shannon R., Heitkemper, Margareth M., Bucher, L., Camera, Ian M. (2011); Medical Surgical Nursing : Assessment and Managemant of Clinical Problems.USA : Elseiver, Mosby. 
Manguma, C., Kapantaw, G.H.M., dan Joseph, W.B.S. (2014). Faktorfaktor Yang Berhubungan Dengan Kepatuhan Pasien GGK YangMenjalani Hemodialisa Di BLURSUP Prof. Dr. R.D Kandau Manado. Universitas Sam Ratulangi Manado. Retrived from https://fkm.unsrat.ac.id/wpcontent/uploads/2014/10/artikelchrismanguma-101511219.pdf

Ningsih, Endang Sri P; Agus Rahmadi; Hammad. (2012). Tingkat Kepatuhan Pasien Gagal Ginjal Kronik Dalam Pembatasan Cairan Pada Terapi Hemodialisa, J urnal Ners, 7, 25-31

Novitasari, D., \& Anita, D. C. (2015). Hubungan Lama Hemodialisis dengan Kepatuhan Pembatasan Asupan Cairan pada Klien Hemodialisis di RS PKU M uhammadiyah U nit I Yogyakarta (Doctoral dissertation, STIKES'Aisyiyah Yogyakarta). Retrieved from http://digilib.unisayogya.ac.id/198/

Potter P. A \& Anne G Perry.(2009). Fundamental Keperawatan (Ed.7). Jakarta: Salemba Medika.

Rostanti, A., Bawotong, J., Onibala, F. (2016). Faktor Faktor Yang Berhubungan Dengan Kepatuhan Menjalani Terapi Hemodialisa Pada Penyakit Ginjal Kronik Di Ruangan Dahlia Dan Melati Rsup Prof. Dr. R. D Kandou Manado. e-journal Keperawatan (e-Kp) Volume 4
Nomor 2. Retrived from https://ejournal.unsrat.ac.id/index.p hp/jkp/issue/view/1401

Savitri, Y. A., \& Parmitasari, D. L. N. (2015). Kepatuhan Pasien Gagal Ginjal Kronis Dalam Melakukan Diet Ditinjau Dari Dukungan Sosial Keluarga. Psikodimensia, 14(1), 110. Retrived from http://journal.unika.ac.id/index.php/ psi/article/view/369

Sepdianto, T. C., Suprajitno, S., \& Usmiati, E. (2017). Penambahan Berat Badan antara Dua Waktu Hemodialisa pada Pasien Gagal Ginjal Kronik yang Menjalani Hemodialisa di RSD Mardi Waluyo Kota Blitar. Jurnal Ners dan Kebidanan (Journal of Ners and Midwifery), 4(1), 064-069. Retrived from

https://jnk.phb.ac.id/index.php/jnk/a rticle/view/0167

Smeltzer, S.C., Bare, B.G., Hinkle, J.L., Cheever, K.H. (2014). Brunner \& Suddarth's Textbook of MedicalSurgical Nursing. $12^{\text {th }}$ ed. Philadelphia : By Wolters Kluwer Health/ Lippincott Williams \& Willkins.

Wahyuni, Irwanti, W., Indrayana, S. (2014). Korelasi Penambahan Berat Badan Diantara Dua Waktu Dialisis dengan Kualitas Hidup Pasien Menjalani Hemodialisa. J urnal Ners dan Kebidanan Indonesia. Vol. 2, No. 2, 51-56. Retrived from file:///C:/Users/ACER/AppData/Loc al/Temp/25-47-4-PB.pdf 